\title{
The Effect of Integrating DARTs on Learners Academic Performance in Rates of Chemical Reaction
}

\author{
Peter Magawaa, ${ }^{a}$, Kabaso Kennedy Kalebailaa, \\ a School of Mathematics and Natural Sciences, The Copperbelt University, P.O. Box 21692, Kitwe, Zambia
}

${ }^{*}$ Corresponding author: magawap@yahoo.com

kkalebai@gmail.com

Received: July 27, 2020; Accepted: November 15, 2020; Published: December 12, 2020

\begin{abstract}
This research examined the effect of integrating DARTs (Directed Activities Related to Texts) on learners' academic performance in rates of chemical reactions at Raphael Kombe Secondary School in Kabwe, Zambia. A total of 105 participants $(\mathrm{N}=105)$ was assigned randomly into control and experimental groups. The control group was taught using collaborative method and the experimental group was taught using DARTs strategy. DARTs strategy is a teaching method which demands a learner centered activity in order to explain the terms and concepts in any science topic hence helps to break the science language barrier. Quantitative data was collected from both groups on three different times using Pre-test, Post-test and Counterbalance test. Quantitative data was tested for normality using Shapiro-Wilk test and normally distributed data was later tested using the Independent samples t-test to compare the achievement mean scores of the two groups. The mean score for the pre- test to both groups was similar at 38, but after intervention in the post test set at $\alpha=0.05$, the experimental mean score was much higher at 71 compared to a mean of 51 for the control group. ( $p$-value $=0.001)$. The mean scores from counterbalance test set at $\alpha=0.05$ showed that the mean score for the control group rose to 62 as compared to the mean score for the experimental group which dropped to 41 . ( $p$-value $=0.001)$. The findings of the study were that DARTs had a positive effect on the learners' academic performance and on the interpretation and retention of scientific terms in rates of chemical reactions. Qualitative data was collected using a questionnaire and it was analyzed using Mann Whitney U-test. The $p$-value from the Mann Whitney U-test was 0.474 greater than the level of significance set at 0.05 . Therefore, DARTs technique had no impact on the attitude of learners towards teaching and learning of rates of chemical reactions.
\end{abstract}

Keywords: DARTs strategy, Performance, Interpretation, Attitude, Rates of Chemical reactions

\section{INTRODUCTION}

Most learners in Zambian secondary schools are taught in English language. This is in line with the government policy, recommended and approved language of instruction in all schools by the Curriculum Development Centre [1]. However, most of science education learners are Limited English Proficiency (LEP) students because they do not use English regularly for everyday communication. Therefore it was prudent that, Directed Activities Related to Terms, DARTs strategy was investigated in order to ascertain its merits and demerits when using it during science lessons as a means to ease the science language barrier. DARTs strategy was originally developed by Lunzer and Gardner [2]. DARTs strategy was developed in order to encourage learners to master concepts or terms in different disciplines in a more detailed and developed cognitive way. The developers of this teaching technique came up with the following advantages for all teachers that used DARTs teaching strategy;

i. $\quad$ DARTs activity is a problem-solving activity hence it promoted and developed analytical skills.

ii. DARTs activity increased engagement as learners got involved in physical activities in order to manipulate the texts.

iii. DARTs activity provided active learning situations in which learners collaborated and cooperated 
to solve problems.

iv. DARTs activity helped to internalize learning and therefore supported the subject teacher's objectives.

v. DARTs tasks enabled learners go beyond the literal level of understanding.

vi. DARTs activity was an excellent way of introducing a new topic, difficult topic or to revise and consolidate a topic at the end of a unit.

The trend for Science performance mean scores at both school and national levels for grade 12 learners in most secondary schools had been poor as depicted in Figure 1. [3].

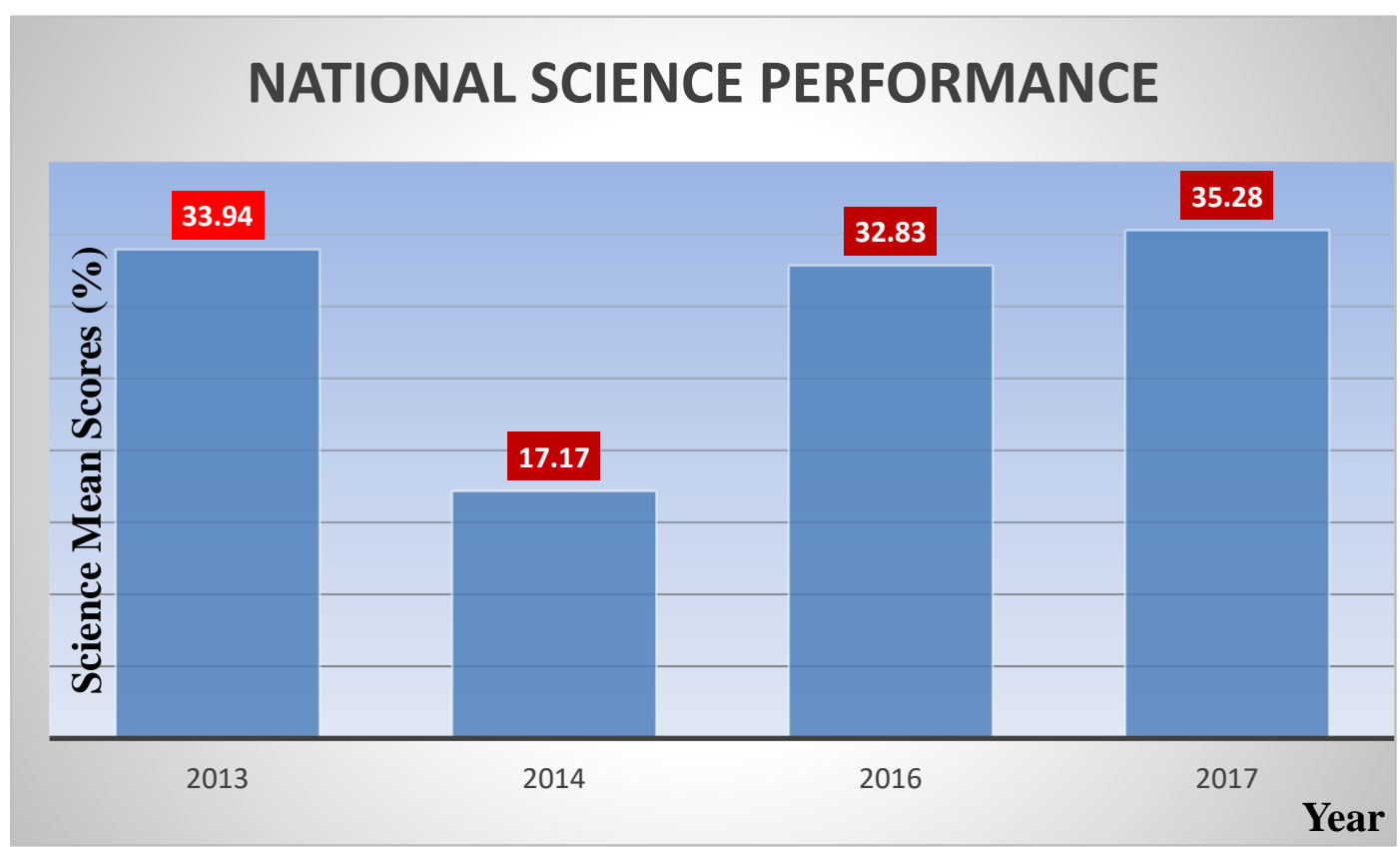

Figure 1. National Science Performance Mean Scores

Some of the reasons highlighted in the Chief Examiner's Report (2017) were that candidates failed to describe in detail all experimental procedures. At both school and national levels, section $\mathrm{C}$ of the science paper two (II) was poorly attempted because candidates lacked understanding of key scientific concepts involved [4]. Examination Council of Zambia (ECZ) chemistry examination paper consists of three sections namely; section $A$, section $B$ and section $C$. Section $C$ comprises of descriptive type of questions which tests candidates' abilities to describe experimental procedures. Most teaching methods do not simplify the language of science hence lead to poor performance of candidates during examinations. Based on ECZ performance statistics it is evident that there is a gap between conceptual understanding of key scientific (terms) concepts and the interpretation of those scientific concepts. Therefore, this study was worthy undertaking because it explored the effects of integrating DARTs activities into learners' attitude, performance and comprehension of the scientific terms, concepts and theories during the teaching of rates of chemical reactions using a Zambian Secondary School Curriculum.

\section{Theoretical Framework}

This research is based on two theories: Bruner's Theory of Experiential and Discovery Learning and Ausubel's Meaningful Learning Theory. Theory of Experiential and Discovery Learning [5] suggested that teachers and teacher educators should provide experiences for inquiry learning in which learners can discover facts and establish relationships for themselves.

Meaningful Learning Theory (Ausubel, [6]) viewed learning as an active process. He suggested that learners must be actively involved in a lesson or activity and they must seek to make sense of their environment by integrating new knowledge being taught in class with what they already learnt. 


\section{Literature review}

Shaw (2002) [7] suggested that teachers and teacher educators should help their learners to analyze their language needs in order to create appropriate learning materials. He emphasized on the need by the teachers to apply more specific strategy in order to help learners comprehend certain passages like reading a simple graph.

DARTs strategy was originally developed by Gardner and Lunzer (1980) [2]. DARTs strategy was developed in order to encourage learners to master concepts or terms in different disciplines in a more detailed and developed cognitive way.

According to Khusniati [8] used DARTs worksheets, focusing on science texts, to improve reading comprehension for science students. Research had suggested that the biggest problem in learning science was from language barrier aspect Wellington [9].

Hilton suggested that science or mathematics education cannot be learned without understanding its language. Further he points out that it is not a matter of committing chemical equations or formulae to learners' memory but acquiring a systematic thought. Bruner [5] stated that teachers do not teach a subject in order to produce little libraries on that subject but rather get learners think scientifically or mathematically for themselves.

\section{METHOD}

\section{Research Design}

This study was based on the positivist paradigm or quantitative approach. A paradigm is a set of basic beliefs that represent a world view, defines the nature of the world and the individual's place in it and helps to determine criteria used to select and define research inquiry. A paradigm guides the types of research questions that will be posed, the methodological approach to the inquiry and the criteria for assessing the trustworthiness of the inquiry. A study by Kirk [10] advocated for the use of a quasi-experimental design in a situation where two or more groups possess the same variables. A quasi- experimental design was used for this study and the results obtained were true reflection of this research inquiry. The Pre-test, Posttest, Counterbalance-test Control group Quasi-Experimental research design was used.

\section{Description of Research Site}

Raphael Kombe Secondary School is a girls' government school located in Ngungu Township, about $8 \mathrm{~km}$ from the Central Business District, (CBD), of Kabwe District, Central Province of Zambia. At the time of the study, the school had a total population of 690 learners, of which 190 were grade eleven learners (Grade $11 \mathrm{~A}=46,11 \mathrm{~B}=51,11 \mathrm{C}=53,11 \mathrm{D}=40$ ), the target population for this study.

\section{Sampling Design}

The simple random sampling technique was employed in drawing the sample. Two grade eleven classes were picked at random with replacement and this was done by writing class names $(11 \mathrm{~A}, 11 \mathrm{~B}$, $11 \mathrm{C}, 11 \mathrm{D}$ ) on pieces of paper, then putting them in the container and finally randomly select two papers from the container. Thereafter the classes that were randomly selected into a research sample were further randomly assigned into either experimental group or control group. Raphael Kombe secondary school has well-structured classes and therefore learners were not individually assigned into either experimental group or control group in order to prevent the disruption of the normal running of the school calendar.

\section{Research Instruments}

This study used the Chemistry Assessment Tests (CAT) and the questionnaire.

\section{Chemistry Assessment Tests}

In order to measure the learners' performance in rates of chemical reactions, performance tests were administered. The performance scale in the tests ranged from $0 \%$ to $100 \%$ and all the test items were 
prepared using Blooms Taxonomy Learning Outcomes. CAT 1 was the pre-test, CAT 2 was the post-test and CAT 3 was the counterbalance test.

\section{Questionnaire}

Questionnaire was developed in order to measure the learners' attitude towards understanding of the concepts of chemical kinetics. The questionnaire contained a five-point Likert scale which was for measuring attitude as a latent variable. The five-point Likert scale ranged from $1=$ strongly disagree to 5 $=$ strongly agree. Attitude is a latent variable comprising of cognitive component, affective component and behavioral component which could be observed in learners Tzougraki [11]. The questionnaire consisted of six questions measuring cognitive component, six questions measuring affective component and six questions measuring behavioral component of attitude.

\section{RESULTS}

\section{Pre-test data set presentation}

The first set of quantitative data was collected from the experimental and control groups of the study at the beginning of data collection process. Both the experimental and control groups were tested on their performance and understanding in rates of chemical reactions before an intervention was implemented. The Chemistry Assessment Test (CAT) administered at this stage was called a Pre-test. The purpose of the pre-test was to assess whether the experimental and control groups were homogeneous or heterogeneous before the commencement of the research process. Knowing either the two groups were homogeneous or heterogeneous helps the researcher identify the likely effects of the outcome from the participants' scores. The results from CAT 1 show that the two groups were homogenous before the start of the research. Experimental $(M=37.5, S D=2.29)$, Control $(M=38.1, S D=2.5)$

Table 1. Pre-Test Scores for Participants $(\mathrm{N}=105)$.

\begin{tabular}{|l|l|l|l|l|l|}
\hline Group statistics & $\begin{array}{l}\text { GROUPS OF } \\
\text { PARTICIPANTS }\end{array}$ & N & Mean & $\begin{array}{l}\text { Std. } \\
\text { Deviation }\end{array}$ & $\begin{array}{l}\text { Std. Error } \\
\text { Mean }\end{array}$ \\
\hline $\begin{array}{l}\text { Pretest } \\
\text { scores for } \\
\text { participants }\end{array}$ & $\begin{array}{l}\text { Experimental } \\
\text { Group }\end{array}$ & 53 & 37.5472 & 2.29184 & 0.31481 \\
& $\begin{array}{l}\text { Control } \\
\text { Group }\end{array}$ & 52 & 38.1731 & 2.50271 & 0.34706 \\
\hline
\end{tabular}

\section{Post-test data set presentation}

The second set of quantitative data was collected from both the experimental and control groups. The second test of CAT was called Post-test, and was administered immediately after implementing the intervention (DARTs). The post-test was used to assess the impact of DARTs on the academic performance of the learners in rates of chemical reactions. After the intervention the experimental group scored much higher in the CAT at a mean of $71(\mathrm{M}=71, \mathrm{SD}=4.3)$ compared to the control group at 50 $(M=50, S D=4.5)$ who were taught using the conventional method as shown in table 2 . DARTs strategy had an impact on academic performance of learners. 
Table 2. Group Descriptive Statistics for Post-Test $(\mathrm{N}=105)$

\begin{tabular}{|l|l|l|l|l|l|}
\hline \multicolumn{7}{|c|}{ Group Statistics } \\
\hline & $\begin{array}{l}\text { GROUPS OF } \\
\text { PARTICIPANTS }\end{array}$ & N & Mean & $\begin{array}{l}\text { Std. } \\
\text { Deviation }\end{array}$ & $\begin{array}{l}\text { Std. } \\
\text { Error } \\
\text { Mean }\end{array}$ \\
\hline $\begin{array}{l}\text { Post-Test } \\
\text { Scores For } \\
\text { Participants }\end{array}$ & $\begin{array}{l}\text { Experimental } \\
\text { Group }\end{array}$ & 53 & 70.9623 & 4.28756 & 0.58894 \\
\cline { 2 - 6 } & Control Group & 52 & 50.25 & 4.45401 & 0.61766 \\
\hline
\end{tabular}

\section{Counterbalance Test}

The third set of quantitative data was collected from both the experimental and control groups. However, the control group was tested by subjecting it to the DARTs technique as a counter balance measure and the experimental group was taught using conventional method. The results shown in Table 3 indicates that mean score for the control group rose to $62.2(\mathrm{M}=62.2, \mathrm{SD}=9.6)$ while the mean score of the experimental group fell to $41.4(\mathrm{M}=41.4, \mathrm{SD}=2.9)$. The results show that DARTs strategy had a significant impact on the interpretation and retention of scientific terms in rates of chemical reactions.

Table 3. Group Descriptive Statistics for Counterbalance-test $(\mathrm{N}=105)$ GROUP STATISTICS

\begin{tabular}{l|lllll}
\hline $\begin{array}{l}\text { Counterbalance } \\
\text { test scores }\end{array}$ & Participants & $\mathrm{N}$ & Mean & $\begin{array}{l}\text { Std. } \\
\text { Deviation }\end{array}$ & $\begin{array}{l}\text { Std. } \\
\text { Error } \\
\text { Mean }\end{array}$ \\
\cline { 2 - 6 } & $\begin{array}{l}\text { Experimental } \\
\text { Group }\end{array}$ & 53 & 41.4423 & 2.94001 & .40771 \\
\cline { 2 - 6 } & $\begin{array}{l}\text { Control } \\
\text { Group }\end{array}$ & 52 & 62.2264 & 9.63895 & 1.3240 \\
\hline
\end{tabular}

\section{DISCUSSION}

\section{What is the impact of DARTs technique on performance in rates of chemical reactions?}

The research question was tested by using Independent samples t-test and the level of significance was set at 0.05 . The performance of the experimental group in the post-test was compared to the performance of the control group in the post-test. The p-value $(0.001)$ for the test was less than the level of significance at 0.05 . Hence, there was enough evidence to reject the null hypothesis. DARTs strategy had an impact on the performance of learners in rates of chemical reactions.

Table 4. Post-Test Independent Samples t-Test $(\mathrm{N}=105)$

INDEPENDENT SAMPLES t-TEST

\begin{tabular}{|c|c|c|c|c|c|c|}
\hline \multirow[t]{3}{*}{$\begin{array}{l}\text { Post- } \\
\text { test } \\
\text { scores }\end{array}$} & & \multicolumn{2}{|c|}{$\begin{array}{l}\text { Levene's test } \\
\text { for Equality of } \\
\text { Variances }\end{array}$} & \multicolumn{3}{|c|}{ t-test for Equality of Means } \\
\hline & & F & Sig & $\mathrm{t}$ & df & $\begin{array}{l}\text { Sig(2- } \\
\text { tailed })\end{array}$ \\
\hline & $\begin{array}{l}\text { Equal } \\
\text { Variances }\end{array}$ & 7.105 & 0.043 & 24.278 & 103 & 0.000 \\
\hline
\end{tabular}




\begin{tabular}{|c|c|c|c|}
\hline \multicolumn{4}{|c|}{\begin{tabular}{|l|} 
Assumed \\
\end{tabular}} \\
\hline $\begin{array}{l}\text { Equal } \\
\text { Variances } \\
\text { not } \\
\text { Assumed }\end{array}$ & 24.269 & 102.663 & \\
\hline
\end{tabular}

\section{What is the impact of DARTs technique on the interpretation and retention of concepts (terms) in} rates of chemical reactions?

The achievement or performance in the post-post-test (counterbalance) of the experimental group was compared to the achievement in the post-post-test of the control group. This test was done to assess whether DARTs technique had any significant impact on learners' interpretation and retention of scientific concepts in rates of chemical reaction. The $p$-value $(0.001)$ for the t-test was less than the level of significance at 0.05 . There was enough evidence to reject the null hypothesis and accept the research hypothesis. DARTs strategy had an impact on the interpretation and retention of concept (terms) in rates of chemical reactions.

Table 5. Post-Post-Test (Counterbalance Test) Independent Samples t-Test $(\mathrm{N}=105)$

\begin{tabular}{|c|c|c|c|c|c|c|}
\hline \multicolumn{7}{|c|}{ INDEPENDENT SAMPLES t-TEST } \\
\hline \multirow[t]{4}{*}{$\begin{array}{l}\text { Counterbalance } \\
\text { test scores }\end{array}$} & & \multicolumn{2}{|c|}{$\begin{array}{l}\text { Levene's test } \\
\text { for Equality of } \\
\text { Variances }\end{array}$} & \multicolumn{3}{|c|}{ t-test for Equality of Means } \\
\hline & & $\mathrm{F}$ & Sig & $\mathrm{t}$ & df & $\begin{array}{l}\text { Sig(2- } \\
\text { tailed) }\end{array}$ \\
\hline & $\begin{array}{l}\text { Equal } \\
\text { Variances } \\
\text { Assumed }\end{array}$ & 42.608 & 0.000 & 14.883 & 103 & 0.000 \\
\hline & $\begin{array}{l}\text { Equal } \\
\text { Variances } \\
\text { not } \\
\text { Assumed }\end{array}$ & & & 15.003 & 61.763 & 0.000 \\
\hline
\end{tabular}

\section{What is the impact of DARTs on learners' attitude towards rate of chemical reactions?}

The Principle Component Analysis (PCA) could only be done on normally distributed attitude score data sets therefore the KMO Measure of Sampling Adequacy and the Bartlett's Test of Sphericity were conducted first. According to Tzougraki [11] PCA empirically examines the interrelationships among the items of the questionnaire, identify clusters of items that share sufficient variation and justify the existence of constructs.

Table 6. KMO Test of Sampling Adequacy and the Bartlett's Test of Sphericity. KMO and Bartlett's Test

\begin{tabular}{lll}
\hline $\begin{array}{l}\text { Kaiser-Meyer-Olkin Measure of } \\
\text { Sampling Adequacy }\end{array}$ & .911 \\
\hline $\begin{array}{l}\text { Bartlett's Test of } \\
\text { Sphericity }\end{array}$ & $\begin{array}{l}\text { Approx. Chi- } \\
\text { Square } \\
\text { df }\end{array}$ & 3260.145 \\
& Sig. & 136 \\
\hline
\end{tabular}

Table 6 shows the KMO test value of 0.911 which is greater than the recommended KMO test value of 0.8 . As a rule of the thumb, KMO values between 0.8 and 1 indicate that the sampling is adequate and suitable for Factor Analysis. 
The third research question was tested in order to assess whether DARTs had any statistically significant impact on the learners attitude towards rates of chemical reactions. The research question was tested using the Mann Whitney U-test because the data was non parametric.

The level of significance was set at 0.05 and the attitudes of the two groups were compared using the SPSS.

Table 7. Mann Whitney U-test.

\begin{tabular}{cc} 
Attitude Comparison using Mann Whitney U-test \\
\hline Mann-Whitney U & 1266.500 \\
Wilcoxon W & 2644.500 \\
Z & -.716 \\
Asymp. Sig. (2-tailed) & .474 \\
\hline
\end{tabular}

Table 7 indicates the Mann Whitney U-test value of 1266.500 and its $p$-value of 0.474 . The $p$-value from the Mann Whitney U-test is greater than the level of significance set at 0.05 . The null hypothesis could not be rejected. Therefore, there was no statistically difference in the attitude scores towards rates of chemical reactions between the learners taught through DARTs technique and learners taught through collaborative method.

This study sought to establish the impact of integrating DARTs teaching strategy on learners' academic achievement in rates of chemical reactions. There were three main variables which came out from the study and these were; performance (achievement), interpretation and attitude.

Table 2 showed the Post-test mean scores for the two groups. The experimental group had a higher mean score in achievement in rates of chemical reactions than the control group. Table 4 showed the post test independent samples t-test in which the p-value (0.001) for the test was less than the level of significance at 0.05 . Hence, there was enough evidence to reject the null hypothesis. Despite other minor factors at play, the large difference in the achievement scores between the experimental group and the control group could only be attributed to the teaching methods used. It was concluded in this research that DARTs technique had a positive impact on learners' achievement in learning rates of chemical reactions.

In Table 3 the control group was tested by subjecting it to the DARTs technique as a counter balance measure and the experimental group was taught using conventional method. The mean score for the control group rose to 62.2 while the mean score of the experimental group fell to 41.4. These results showed that learners had a better understanding and interpretation of scientific terms in rates of chemical reactions. Table 5 showed the counterbalance test independent samples t-test in which the $p$-value $(0.001)$ for the test was less than the level of significance at 0.05 . Hence, there was enough evidence to reject the null hypothesis. It was also concluded in this research that DARTs technique had a positive impact on learners' interpretation and understanding of scientific terms in learning rates of chemical reactions.

Table 7 showed that there was no statistically significant difference in the attitude ranks between the learners taught using DARTs technique ant those taught using conventional methods. There was no evidence to reject the null hypothesis therefore it was concluded that DARTs technique had no impact on the learners' attitude towards learning rates of chemical reactions.

\section{CONCLUSION}

The study had three research questions and it was concluded that DARTs technique had a positive impact on both the achievement scores and improved interpretation and retention of scientific terms in learning of rates of chemical reactions in chemistry. However, DARTs technique had no significant impact on the learners' attitude towards learning of rates of chemical reactions.

\section{REFERENCES}

1. CDC. (2013). Chemistry Syllabus. Lusaka: Curriculum Development Center.

2. Lunzer, G. H. (1980). Frames of Mind: The Theory of Multiple Intelligencies. Basic books.

3. ECZ. (2013/2014). Examinations Performance Review Booklet. Lusaka: Examinations Council of Zambia. 
4. ECZ. (2016/2017). Examinations Performance Review Booklet. Lusaka: Examinations Council of Zambia.

5. Bruner. J. (1960). The Process of Education : Towards a Theort of Instruction. Cambridge: MassBelkapp Press.

6. Ausubel. D. (1968). Education Pschology : A Cognitive View. New York: Holt, Rinehalt and Winston.

7. Shaw, G.B. (2002). Linguistically Responsive Science Teaching. Electronic Magazine of Multicultural Education

8. Khusniati, P. A. (2012). DARTs for developing process skills and critical thinking. International Journal of Engineering and Technology , 570-573.

9. Wellington, H. A. (1998). Lowering the language barrier in learning and teaching science. School Science Review, 35-46.

10. Kirk, R. (1995). Experimental Design: Procedures for Behavioural Sciences (3rd Edition). Brooklyn: Brook/Cole.

11.Tzougraki, K. S. (2004). Attitude Towards Chemistry among 11th grade high schools in Greece. Science Education , 88(4). 